\title{
Research on the Validation of Integrated Quality Management System
}

\author{
Li sheng \\ International School \\ Wuhan University of Science and Technology \\ Wuhan, China \\ e-mail: lisheng@wust.edu.cn
}

\begin{abstract}
In validating the IQM system as a model for business excellence, Hypotheses 1 and 2 are true; showing that self-assessment using the Maturity Assessment Grid facilitates objectivity by identifying the grids that are pertinent to the Maturity Level of Quality Contents and Quality Deployment. This contributes to the precision in self-assessment, with consistency in evaluating the organisation's maturity level in their journey for business excellence. The positive responses from the SQC organisations have further reinforced the features that characterised the IQM system, which can be used as the system for business excellence.
\end{abstract}

\section{Keywords-validation; quality; hypothesis; self-assessment}

\section{INTRODUCTION}

This paper reports on the quantitative studies, in validating the IQM system. Validation was carried out with MRC to illustrate usefulness of the IQM system and how self-assessment results are used to determine areas for improvement. The results obtained are converted into Points for SQA Criteria, and compared with results obtained from using the BEACON instrument. The findings and results were also used as the bases for verifying the IQM system.

\section{HYPOTHESES}

\section{A. Hypothesis 1}

In purporting the requirements of an IQM system contextual assumptions provides the logical flow of organisational contexts in contributing to the understanding of its maturity and shaping the organisation's capability to support its own strategy and performance improvement. Understanding the contexts requires us to evaluate the quality dimensions of their contents which underlie their management approach and deployment. In other words, to establish the quality contents and assess the extent of management practices which are relevant to the organisations. This is done through the relevance of the alignments between contexts and contents, and assessing their relationships that guides business excellence.

Hypothesis 1: In my contextual assumptions for Integrated Quality Management, Planning is the context in which its Management Responsibility is the prevalent quality content for business excellence.

This hypothesis surmises that for business excellence, Planning requires Management Responsibility in developing a quality management system that sustains and reinforces the organisation in achieving its goals and objectives. Management Responsibility in this context requires leadership, commitment and active involvement of top management in setting directions, with the aim of improving the organisation's performance. Thus I infer Management Responsibility of Planning has to be leading alignment within the organisational contexts for business excellence. This alignment in the Decision Matrix has to be the thrust in providing management guidance for the other organisational contexts in regards to their intents and performances. The theoretical conjectures can also be substantiated by some objective findings :

- Summary of self-assessment benefits by different researchers,

- Importance of self-assessment benefits to the SQC organisations,

- Maturity level of quality management system of SQC organisations.

For the purpose of evaluation, these values are ranked according to their score with weighted values of 1 (lowest score) to 4 (highest score) for the respective organisational contexts, Table 1 . By adding up the weighted values of the respective columns, Planning has the highest value of the four organisational contexts.

\section{B. Hypothesis 2}

With reference to Scoring systems of MBNQA and SQA [Section 2.7.1], Blazey [2000, 2002], Porter and Tanner [1996], and Conti [1997b], I also deem that the Likert scale is not an effective instrument for self-assessment. This is also acceded by the SQC organisations in using the BEACON instrument for SQA self-assessment. In the Survey on Organisational Self-assessment using Business Excellence Criteria (Appendix C - item Q.11), 89\% of the 73 respondents do not agree that the instrument is effective for self-assessment. In addition to the inherent weaknesses of Likert scale, I also think that BEACON instrument is unable to facilitate systematic objective assessment. By providing the "checklists", it is difficult to determine the management practices and evaluate their contents that are relevant to business excellence. I attempt to address these deficiencies through replacing the Likert scale with the MAG instrument, Table 2. By incorporating this instrument in the assessment of IQM system, I seek to improve the process of selfassessment and offer an alternative in the evaluation of SQA criteria. In substantiating the effectiveness of my approach 
and relevance of quality contents in the IQM system, I conjecture that criteria for business excellence can also be evaluated via the maturity of the IQM system. To be explicit, my second hypothesis is set to prove that when using MAG there is a strong correlation in the results obtained from BEACON instruments with self-assessment of IQM system, in which the Pearson correlation must be greater than 0.9 . Due to the objectivity and step-wise approach of the selfassessment grid, and the deployment of quality contents, assessment results base on SQA criteria will be lower for IQM system as compared to the BEACON instrument.

Hypothesis 2: With reference to the SQA criteria, selfassessment using the Maturity Assessment Grid is an alternative in evaluating organisations in their journey for business excellence, where the results obtained is lower with IQM system as compared to the BEACON instrument.

The use of matrices for self-assessment and business improvement are not new [Cabinet Office, 1996; MacKerron and McGlynn, 2000]. However, assessment on the maturity of quality management practices which are based on quality contents and customised to organisation's needs is a novel one. Although, I infer the SQA results obtained from the IQM system is lower, my intention is to be unambiguous in providing an effective approach for performance improvement and fact-based guidance that allows a gradual development from the basic foundations of ISO 9000 to all the encompassing requirements for business excellence.

\section{VALIDATION OF IQM SYSTEM}

In validating the IQM system as a model for business excellence, my findings have proven that Hypothesis 1 is true. With reference to the case study on MRC, selfassessment of its quality contents has indicated that Planning is the dominant context of IQM system.

In the self-assessment of MRC using the MAG instrument, Planning has the highest average score of 53.4\%. It is the dominant organisational context, where its Management Responsibility (54.7\%) is the prevalent quality content that sustains and reinforces the organisation in their drive for business excellence.

Management Responsibility is prevalent in Planning context indicates the involvement of top management in setting, direction and purpose of MRC, and improving people commitment to performance. This is done by creating and maintaining an internal environment in which all service managers, commissioned officers and other ranks are involved in achieving MRC's goals and objectives, which are aligned with its vision and mission. The integration of quality management principles into the core values and customised into quality practices also helps to promote policies, values and awareness that encourage motivation and involvement of the people in MRC.

By assigning values of 1 to 16 to respective alignments in the Decision Matrix, with 16 being the highest, I am able to discern the score of its quality contents, Table 3 , where Resource Management has the highest value, i.e. 37.0 out of 136 points. As a service oriented organisation, I am not surprise, since the emphasis on people as a resource is necessary for its success. In view of the four organisational contexts, Planning is also dominant with highest value in their respective quality contents.

From the Decision Matrix, I have also arranged the four aggregate scores of organisational contexts in a descending order. This helps us to rationalise my contextual assumptions for MRC, through the evaluation of the quality management practices.

Planning $(53.4 \%)>$ People $(52.3 \%)>$ Performance $(45.4 \%)>$ Project $(44.5 \%)$

- The current setting of MRC is its emphasis in Planning as a strategy which involves top management in developing purpose, vision and values that are concerned with the overall intent in achieving the organisation's goals and objectives.

- People context takes on Planning in developing the potentials of the workforce that are customer focus and in contributing to the achievements of MRC's goals and objectives. This context ensures that people are motivated and adaptable to change in meeting customer requirements, with the aim of enhancing customer satisfaction and confidence.

- Performance context takes upon the development of people in managing performance improvement, by identifying the processes and examining their results that are critical to MRC's goals and objectives. This includes new processes or processes that are re-designed. Process management ensures that customer requirements are met and continually improved through the analysis and review of results.

- $\quad$ Project context involves the management of results as information for improving the goals and objectives. This context reinforces innovation with effective use of information and results to support decision making, by which performance improvement is achieved. In view of the low Percentage scores (B) of Result criterion, it is expected that this context has the lowest value. The compilation of results as information is necessary to support the Project context, which in my case study is relatively weak.

For Hypothesis 2, the variables A1, A2 and A3 are used to validate the IQM system. Statistical paired- $t$ tests using the following test statistics can be used to analyse the score data at $\alpha$ level of significance:

$$
t=\frac{\bar{d}-\mu_{d}}{s_{d} / \sqrt{n}}
$$

where $n$ is the sample size under study; $\bar{d}$ denotes the sample average of the differences

between the two methods being compared; $\mu_{d}$ represents the population mean; ${ }^{S_{d}}$ denotes the standard 
$s_{d} / \sqrt{n}$ deviation of the 'difference' varic

mean difference. Hence using $\alpha=5 \%$, from the extremely small significant probability values ( $p$ values are zero), it is evident that there is a significant difference between the results obtained using A1 and results obtained with A3. Similarly, in comparing results obtained using A1 with more intermediate results of A2 also show a significant difference. This is also true between the results of A3 and A2. These $p$ values show that there are significant differences in the three methods of self-assessment. 95\% confidence intervals are also constructed for the three pairs of mean difference and as we would expect, none of these intervals contain the value zero.

On average, the self-assessment using IQM system will generally lead to lower scores as compared to other methods that use the BEACON instrument. These findings are expected because the method of self-assessment using IQM system is objective and have to be supported by evidence and/or results. The findings are supported by the following observations with MRC:

- The auditing elements that are incorporated into self-assessment of IQM system has contributed to the accuracy of findings and consistency in the evaluation. This has decreased the range of variation, where subjectivity of evaluations has to be supported, rationalised and agreed by the assessors.

- The scope of quality management practices are only pertinent to the alignment, wherein ownership in managing the quality contents is clearly defined and the extent of their deployment has to be validated. This has decreased the ambiguity in the deployment of quality management practices.

- The reliability and completeness in the gathering and collation of data and information illustrates a contribution to lower score, since objectivity of information and has to be verified before it is actually used for evaluation against practices.

Further analysis using the BEACON instrument with MAG is explored to ascertain whether there is an underestimate or the results can be relied upon with confidence. It shows the mean value of A1 is 48.41, which is smaller than A2 and A3, where their means values are 52.14 and 55.32 . This confirms my findings that the method of selfassessment using the IQM system will generally give rise to lower assessment scores as compared to the BEACON instrument with MAG and BEACON instrument with Likert scale.

Pearson correlation analysis was also carried out to measure the strength of the relationship between two different methods of self-assessment. In the case of strong positive Pearson correlation, it implies that two random variables under study will both tend to be relatively large at the same time and relatively small at the same time. This indicates close associations in the results despite different self-assessment instruments are used. From the correlation coefficients, it is observed that there are strong positive associations between all three methods of self-assessment. Within the accepted scoring band of $\pm 10 \%$ range, there is a strong correlation between A1 and A2, i.e. assessment using IQM system and BEACON instrument using MAG, Pearson correlation is equal to 0.957 . This result also conforms to the criteria in testing Hypothesis 2, where Pearson correlation (r) between IQM system and BEACON instrument must be greater than 0.9. By using the same source for testing the hypothesis, I deduce that there is a strong correlation between IQM system and BEACON instrument, when the same scoring system, MAG, is used. The correlation indicates that with the same scoring system, IQM system can be an alternative to BEACON instrument in the evaluation of business excellence.

In validating Hypothesis 2, correlation value is smaller when different scoring system is used. Pearson correlation between A1 and A3 is 0.892 and does not conform to the hypothesis test, where Pearson correlation has to be greater than 0.9. From the result, I conclude that the gap between results obtained using BEACON instrument with Likert scale and the IQM system is wider. I attribute this association to the different instruments of self-assessment and scoring systems. However for the same BEACON instrument, but with different scoring system, Pearson correlation between $\mathrm{A} 2$ and $\mathrm{A} 3$ is equal to 0.915 . This shows that there is consistency in the self-assessment when the same instrument is used; despite the difference in the scoring system of Likert scale and MAG.

Despite the different degrees of accuracy and objectivity, the correlation results obtained also show that the IQM system and BEACON instrument with MAG, are appropriate for use because they are consistent with the present method of scoring. This is affirmed by conducting the Paired T-test, where mean difference between A1 \& A2 (3.727) is less than A1 \& A3 (6.909), where:

- $\quad 95 \%$ CI for mean difference between A1 and A2-.(4.657, -2.797), and

- $\quad$ 95\% CI for mean difference between A1 and A3: (8.562, -5.256).

The mean differences from the T-test are also less than $10 \%$, the accepted variance in SQA award assessment.

From the analyses I deduce that the two hypotheses set to verify the IQM system are true. The results also conclude that there is a stronger correlation in the results when MAG is used as the instrument for scoring, i.e. A1 and A2 as compared to A2 and A3. Although the IQM system and BEACON instrument are different approaches for business excellence, a common scoring system with MAG has improved the consistency and objectivity in the method of selfassessment, with 454 points for IQM system and 488 points for BEACON instrument. These results are compared with 519 that are based on the SQA criteria with Likert scale, where the percentage scores are higher. As in agreement with Blazey [2000 and 2002], my validation of IQM system with MRC also points out that Likert scale gives a snap-shot of the organisation's in meeting the criteria for business excellence. However, it is subjective with higher scores in 
the SOA criteria, and is difficult in quantifying the maturity level of quality management.

\section{CONCLUSION}

In validating the IQM system as a model for business excellence, Hypotheses 1 and 2 are true; showing that selfassessment using the Maturity Assessment Grid facilitates objectivity by identifying the grids that are pertinent to the Maturity Level of Quality Contents and Quality Deployment.

In conclusion, self-assessment using the IQM system can provide a systemic method for evaluating the organisations' progress and achievement. Performance improvement means that top management must continually monitor progress, based on facts and evidences, to identify what has gone well and what needs improving; then develop the strategies and action to increase the pace of improvement.

\section{ACKNOWLEDGMENT}

The author would like to thank Puah Kok Yong for his support and providing invaluable materials and advice.

Table 1 Summary and evaluation of organisational contexts

\begin{tabular}{|c|c|c|c|c|c|}
\hline $\begin{array}{l}\text { Organisational } \\
\text { contexts }\end{array}$ & Planning & People & Project & Performance & Remarks \\
\hline \multirow{2}{*}{$\begin{array}{l}\text { Importance of } \\
\text { self-assessment }\end{array}$} & 3.27 & 3.28 & 3.21 & 3.61 & Scale: 1 to 5 \\
\hline & 2 & 3 & 1 & 4 & Weighted value \\
\hline \multirow{2}{*}{ Maturity of QMS } & 2.72 & 2.01 & 2.39 & 2.64 & Scale: 1 to 5 \\
\hline & 4 & 1 & 2 & 3 & Weighted value \\
\hline \multirow{2}{*}{$\begin{array}{c}\text { Self-assessment } \\
\text { benefits reported } \\
\text { by researchers }\end{array}$} & 45 & 40 & 36 & 39 & \\
\hline & 4 & 3 & 1 & 2 & Weighted value \\
\hline Weighted score & 10 & 7 & 4 & 9 & \\
\hline
\end{tabular}

Table 2 Self-assessment scoring grid, basis for developing MAG

\begin{tabular}{|c|c|c|c|c|}
\hline Maturity level & Performance level & Intent & Approach & Evidence and/or results \\
\hline 1 & No formal approach & & & \\
\hline 2 & Reactive approach & & \multirow{3}{*}{ 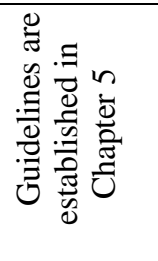 } & \\
\hline 3 & $\begin{array}{l}\text { Stable formal system } \\
\text { approach }\end{array}$ & & & \\
\hline 4 & $\begin{array}{c}\text { Continual } \\
\text { improvement emphasised }\end{array}$ & & & \\
\hline 5 & $\begin{array}{l}\text { Best-in-class } \\
\text { performance }\end{array}$ & & & \\
\hline
\end{tabular}

Table 3 Weighted values of Decision Matrix

\begin{tabular}{|c|c|c|c|c|c|}
\hline 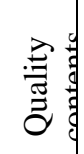 & 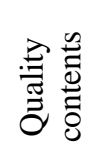 & $\begin{array}{l}\text { Organisational contexts of } \\
\text { IQM SYSTEM }\end{array}$ & $\begin{array}{c}\text { Percentage score of } \\
\text { alignments from Decision } \\
\text { matrix }\end{array}$ & $\begin{array}{l}\text { Weighted value } \\
\text { assigned to the } \\
\text { alignments }\end{array}$ & 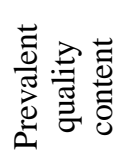 \\
\hline
\end{tabular}

[1] ISO 9000:2000 Quality management systems- Fundamentals and (n) International Organization for standardrisation.

9004:2000 Quality management systems- Guidelines for performance improvements, The International Organization for standardrisation.

3] Yaacob, I. [2002], Reinventing Singapore: Challenges, Strategies and

Sousa, R [2001], Quality Management Practice: Universal or Context Dependent? An Emperical Investigation, Doctoral Thesis, London Business School, University of London.

5] Productivity and Standards Board, Singapore [2001], 2001 Singapore Assessors, February. Excellence,McGrawHill, London.

7] Blazey, M.L.[2002],Insights to Performance Excellence, 2002,ASQ Quality press, Milwaukee, Wisconsin.. 


\begin{tabular}{|c|c|c|c|c|}
\hline \multirow{4}{*}{ 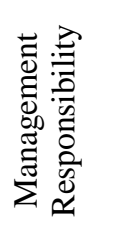 } & Planning & 54.7 & 16.0 & \multirow{4}{*}{$\stackrel{n}{m}$} \\
\hline & People & 52.6 & 12.0 & \\
\hline & Project & 43.5 & 2.5 & \\
\hline & Performance & 40.9 & 1.0 & \\
\hline \multirow{4}{*}{ 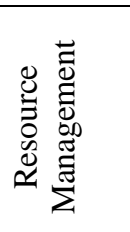 } & Planning & 53.4 & 15.0 & \multirow{4}{*}{ 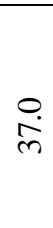 } \\
\hline & People & 52.8 & 13.0 & \\
\hline & Project & 43.5 & 2.5 & \\
\hline & Performance & 47.2 & 6.5 & \\
\hline \multirow{4}{*}{ 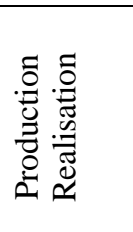 } & Planning & 52.5 & 11.0 & \multirow{4}{*}{$\begin{array}{l}\text { 뭉 } \\
\text { 角 }\end{array}$} \\
\hline & People & 52.2 & 10.0 & \\
\hline & Project & 47.2 & 6.5 & \\
\hline & Performance & 48.9 & 8.0 & \\
\hline \multirow{4}{*}{ 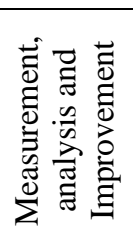 } & Planning & 53.1 & 14.0 & \multirow{4}{*}{$\stackrel{\text { ì }}{\text { min }}$} \\
\hline & People & 51.5 & 9.0 & \\
\hline & Project & 43.9 & 4.0 & \\
\hline & Performance & 44.7 & 5.0 & \\
\hline
\end{tabular}

